\title{
Association Between Erectile Dysfunction and Cardiovascular Disease: A Systematic Review
}

\author{
Sumon Rahman Chowdhury ${ }^{1^{*}}$ \\ Masud Karim ${ }^{1}$ \\ S M Amanat Ullah² \\ Muhammed Abu Bakar
}

1 Department of Diabetes, Endocrinology and Metabolism Chattogram Diabetic General Hospital Chattogram, Bangladesh.

${ }^{2}$ Department of Diabetes, Endocrinology and Metabolism Chattogram Medical College Chattogram, Bangladesh.

${ }^{3}$ Department of Diabetes, Endocrinology and Metabolism Chattogram Maa Shishu-O-General Hospital Chattogram, Bangladesh.
*Correspondence to:

Dr. Sumon Rahman Chowdhury Senior Medical Officer

Department of Diabetes, Endocrinology and Metabolism Chattogram Diabetic General Hospital Chattogram, Bangladesh.

Mobile : +8801670393031

Email:sumonrahman79@yahoo.com

Date of Submission : 13.02 .2019

Date of Acceptance $\quad$ : $\quad 30.06 .2019$

www.banglajol.info/index.php/CMOSHMCJ

\begin{abstract}
Erectile Dysfunction (ED) describes the persistent inability to achieve or maintain a penile erection for adequate sexual performance.

$E D$ is thought to be a vascular disease affecting more than $70 \%$ of men with (Cardiovascular Disease) CVD and sharing a myriad of risk factors like hypertension, smoking, diabetes, obesity, ageing and the metabolic syndrome.

Diabetes increases the risk of both ED and CVD with the latter being the leading cause of death.

Endothelial dysfunction and its role in the development of atherosclerosis may be the common link between ED, CVD and diabetes. With the current epidemic of type 2 diabetes, diabetes related CVD will increase in tandem. Early identification of this risk group is therefore paramount.

Evidence has shown that ED is an independent marker of increased CVD risk and heralds the onset of coronary artery disease, peripheral arterial disease and stroke thereby providing a window of opportunity for risk factor modification.

In our paper we shall explore the correlation of ED and CVD with a view to formulation of intervention strategies.
\end{abstract}

Key words: ED; CVD; Risk factors.

\section{INTRODUCTION}

Erectile Dysfunction (ED) and Coronary Artery Disease (CAD) are common in diabetic patients. In a study conducted in Bangabandhu Sheikh Mujib Medical University (BSMMU), Bangladesh Institute of Research and Rehabilitation in Diabetes, Endocrine and Metabolic Disorder (BIRDEM) and 4 other diabetes centers in Dhaka, Bangladesh, the frequency of ED in Bangladeshi diabetic men was $53.98 \%$. The studies also found ED to be significantly associated with age ${ }^{1}$. The observations from recent studies suggest there is an association between ED and CVD as they share common pathophysiological mechanisms and in fact ED may be used as a predictive marker of future CAD. These findings may potentially have huge impact on our approach to aggressive cardiovascular risk factors modifications in diabetic patients with ED and there are a number of ongoing trials aiming to evaluate this relationship further.

The pathophysiology of ED in diabetes is multifactorial. Factors like endothelial dysfunction, autonomic neuropathy, hypogonadism, drug side effects and traditional CV risk factors are all implicated. ED predicts CVD therefore risk stratification with appropriate lifestyle modification and pharmacotherapy provides a window of opportunity to intervene in this high risk group.

Our paper summarizes what we know so far on the associations between ED and CVD on the molecular level and reviews the trial data and guidelines on effective treatment strategies. 


\section{Search Strategy}

Available studies and abstracts were identified through Pub Med and Medline data bases (From 1980-2015) and Cochrane data bases. Key search terms were erectile dysfunction and cardiovascular disease. All available studies and abstracts describing the relationship between Erectile Dysfunction and Cardiovascular disease were included. The reference list of review articles were also searched.

\section{DISCUSSION}

\section{Physiology of Penile Sexual Function (Figure 1)}

The main components of penile erectile tissue are the cavernous smooth musculature and the smooth muscles of the arteriolar and arteriole walls. During the flaccid state they remain tonically contracted. When sexual stimulation occurs, the release of neurotransmitters leads to smooth muscle relaxation which causes dilatation of the arterioles and arteries, blood entrapment in the expanding sinusoids, reduction of the venous outflow, increase in the intracavernous pressure and contractions of the ischocavernous muscles leading to erection $^{2,3}$. The hemodynamic changes in corpus spongiousm and glans penis are similar but there is a much smaller rise in the pressures with minimal venous flow occlusion.

The penile tissue is innervated by somatic as well as autonomic pathways (Sympathetic and parasympathetic) but central neural activation during sexual arousal also plays a significant role ${ }^{3}$.

The crucial role in the smooth muscle contraction and relaxations is played by cytosolic free calcium and the RhoA/Rho kinase pathway ${ }^{3}$.

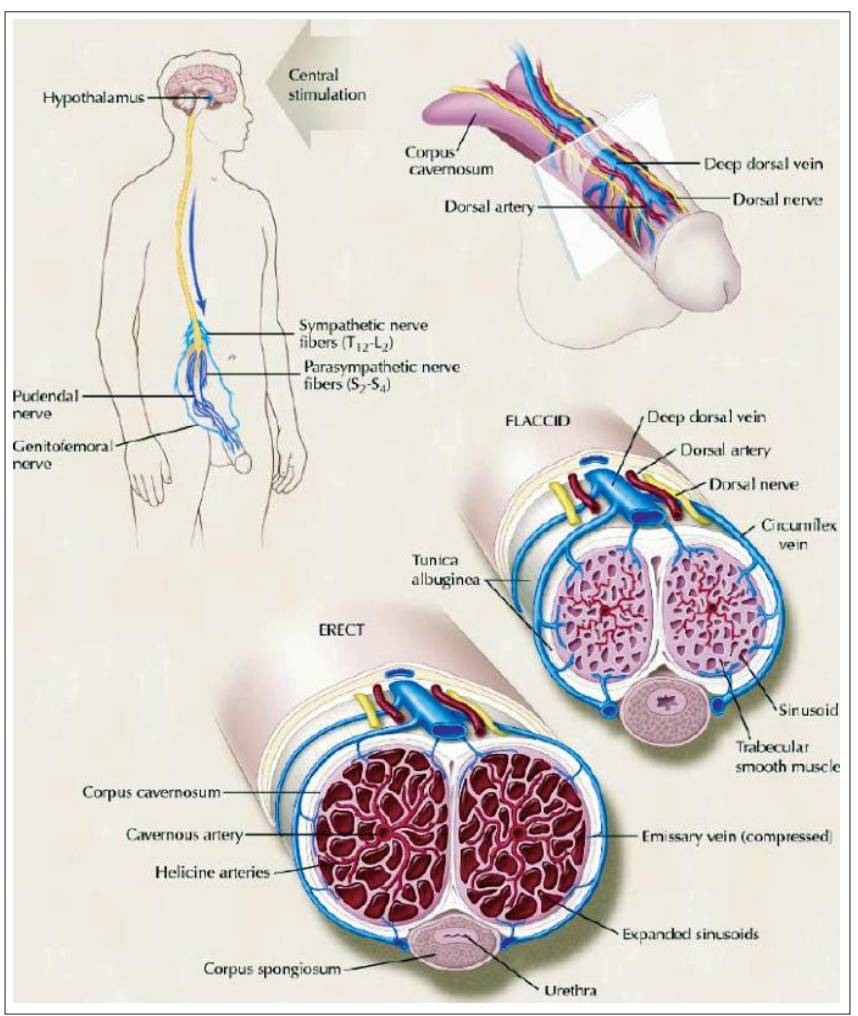

Source Figure 1 : Physiology of erection

(Adapted from http://ukonlinetablets.com/blog/physiology-ofan-erection.html)
Prevalence of Erectile Dysfunction

Worldwide, ED is estimated to affect over 100-150 million men occurring with greater frequency in diabetic males ${ }^{4,5}$. The prevalence increases with age, disease duration and severity of diabetes $^{6}$. ED can present $10-15$ years earlier in the diabetic male compared to their non-diabetic counterparts ${ }^{7}$.

In the Massachusetts Male Aging Study the incidence of ED increased with diabetes and hypertension after adjusting for age $^{8}$.

A subsequent world literature review found ED prevalence to be between $35-90 \%$ in men with $\mathrm{DM}^{9}$. The wide range can be attributed to difference in the sensitivity and specificity of methods used to assess ED.

There is a paucity of data as to whether ED is more common in men with T1DM or T2DM.

A study of diabetic men with increased BMI, showed those with Type1 Diabetes (T1DM) have a greater risk of ED than those with Type 2 Diabetes (T2DM) with age adjusted prevalence also higher in T1DM at 51\% than T2DM at 37\% in a rather significant way ${ }^{10}$. Miccolo et al. however, demonstrated a greater incidence of ED in T2DM (52\%), than in $\operatorname{T1DM}(40 \%)^{11}$.

ED Risk Factors ${ }^{12}$ :

- Age: Incidence increases with age, ranging between $6 \%$ in young men and $52 \%$ in men in their fifties ${ }^{13}$

- Obesity: The higher the BMI, the higher the ED incidence and severity

- Hyperlipidemia: Hypercholesterolemia and hypertriglyceridemia significantly increase the risk and severity of ED and it is the most common risk for ED

- Smoking

- Hypertension: Diabetic men with hypertension have a higher incidence of ED-76.3\% vs 55.6\% in normotensive diabetic patients $^{14}$

- Duration of diabetes ${ }^{14}$.

Pathophysiology of DIED (Diabetes Induced Erectile Dysfunction) (Figure 2)

\section{Elevated Levels of Advanced Glycation End Products} (AGEs)

AGEs in cavernosal tissue cause thickening and dysfunction of vascular endothelium, reduced elasticity and atherosclerosis by forming covalent bonds with vascular collagen ${ }^{15}$.

\section{Impaired NO Synthesis and Reduced Cyclic Guanosine} Monophosphate (cGMP)

Studies have revealed decreased levels of (eNOS) and (nNOS) which are involved in the production of $\mathrm{NO}$ in the endothelium of the penile arteries; as well as the nitrergic neurons. Thus cavernosal smooth muscle relaxation is impaired through decreased formation of cGMP, which can be caused by a decreased Protein Kinase-1(PKG-1) level, which has a direct effect on the activity of guanylylcyclase and AGEs through 
generation of Oxygen radicals; hence leads to induction of oxidative cell damage and quenching of NO which is further reduced by up-regulation of Rho-Kinase pathway ${ }^{15}$.

In addition the functional syncytium of the corpora cavernosa is quickly rendered ineffective to $\mathrm{NO}^{15,16}$.

Increase of Endothelin-B Receptor (ET-B)

The increase in ET-B receptor and its ligand in the endothelium of the cavernosal blood vessels results in penile vasoconstriction.

\section{Neuropathic Damage}

Autonomic and somatic nerve dysfunction that occurs early in diabetic patients can cause abnormal bulbar urethral and urethro-anal reflexes as well as longer latencies in the pudendal nerves evoked potentials. A central neuropathy also may have a role in $\mathrm{DIED}^{15,16}$.

\section{Loss of Bcl-2 Expression}

Cavernosal smooth muscle atrophy can be caused by loss of Bcl-2 expression. This atrophy is replaced by collagen tissue due to TGF-B leading to a reduction of the compliance of the erectile tissue ${ }^{16}$.

\section{Endothelial Dysfunction}

Endothelial dysfunction and vascular diseases are thought to be the leading cause of ED.

The arterioles, which are lined by smooth muscle, are unable to relax due to endothelial dysfunction; the resulting inhibition of relaxation of smooth muscle can cause vasoconstriction ${ }^{17,18}$.

L-arginine infused diabetic men with ED were found to have a lower reduction in blood pressure and platelet aggregation response (Marker of endothelial function) than those in diabetic men without $\mathrm{ED}^{17}$.

Nitric oxide deficiency can lead to ED through preventing the intracavernosal blood pressure from rising to a level sufficient enough to impede venous outflow.

Atherosclerosis of hypogastric artery and diabetes are examples of decreased blood flow and inadequate intracavernosal oxygen levels ${ }^{19}$.

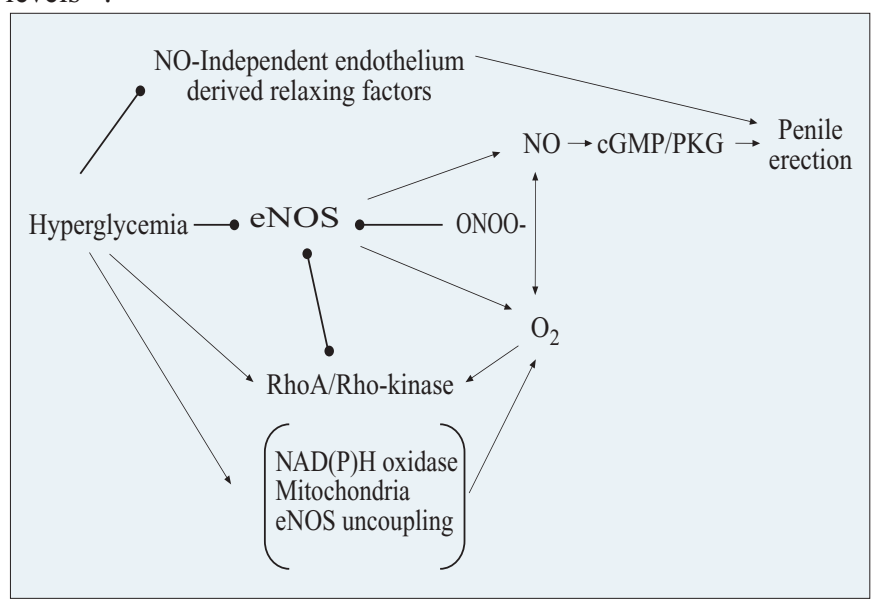

Figure 2 : Summarizes the biochemical mechanisms of endothelial dysfunction
Low Testosterone Pathophysiology of CVD and ED

The levels of Testosterone have been reported to be related inversely to the risk of Major Adverse Cardiac Events (MACEs) and to Coronary Artery Disease (CAD) mortality ${ }^{20-22}$.

Testosterone plays a major role in the control of sexual function, acting both centrally and peripherally, and hypogonadism is frequently associated with ED.

The main targets for androgen effects are the smooth muscle cells and endothelium in CVD system and penile, and atherosclerotic vascular remodeling is associated with an increased risk of hypogonadism ${ }^{23}$.

The expression of inflammatory markers in these tissues can be reduced by Androgens, and low testosterone levels have a proinflammatory and pro-apoptotic effect on endothelial cells ${ }^{24}$.

Subclinical chronic inflammation might further impair endothelial function, leading to a prothrombotic status ${ }^{25}$.

Low androgens levels thus might represent a common link in the pathophysiology of ED and CVD, partially explaining the relationship between CVD \& ED.

\section{Other Factors Contributing to ED in Diabetes}

Obesity is common risk factor for ED. Hypogonadism secondary to obesity is also the major contributing factor for both ED and CVD.

In addition to endothelial dysfunction and autonomic neuropathy, ED is associated with other conditions common in diabetes, such as hypertension and large-vessel disease ${ }^{6}$. Furthermore, men with diabetes are more likely to be taking medications that can lead to ED.

\section{Medications associated with erectile dysfunction}

\section{Antihypertensives}

- Thiazide diuretics

- Beta-blockers

- Calcium-Channel blockers

- Angiotensin-Converting Enzyme (ACE) inhibitors

- Central sympatholytics (Methyldopa, clonidine)

Antidepressants

- Tricyclics

- Monoamine oxidase inhibitors

- Selective serotonin inhibitors can cause ejaculatory problems

Major tranquilizers

- Phenothiazines

- Haloperidol

\section{Hormones}

- Luteinizing hormone-releasing hormone (Goserelin, Buserelin)

- Estrogens (Diethylstilbesterol/stilbesterol)

- Anti-androgens (Cyproterone)

\section{Miscellaneous}

- 5-alpha reductase inhibitors (Finasteride)

- Statins (Simvastatin, atorvastatin, pravastatin)

- Cimetidine

- Digoxin

- Metoclopramide

- Allopurinol

- Ketoconazole 
- Non-steroidal anti-inflammatory agents

- Fibrates

Drugs of "abuse" / "social" drugs

- Alcohol

- Tobacco

- Marijuana

- Amfetamines

- Anabolic steroids

- Barbiturates

- Opiates

Antihypertensive agents are commonly reported to be associated with ED, although much of the evidence is anecdotal; beta-blockers and thiazide diuretics are the most commonly reported culprits, alpha-blockers perhaps have the lesser risk ${ }^{26,27}$.

Finally, it should be remembered that there are many other potential causes of ED unrelated to diabetes, from which men with diabetes are not immune.

\section{Conditions associated with erectile dysfunction}

\section{Psychologic disorders}

- Anxiety about sexual performance

- Psychologic trauma or abuse

- Misconception

- Sexual problems in the partner

- Depression

- Psychoses

Vascular disorders

- Peripheral vascular disease

- Hypertension

- Venous leak

- Pelvic trauma

Neurologic disorders

- Stroke

- Multiple sclerosis

- Spinal and pelvic trauma

- Peripheral neuropathies

\section{Endocrine and metabolic disorders}

- Diabetes

- Hypogonadism

- Hyperprolactinaemia

- Hypopituitarism

- Thyroid dysfunction

- Hyperlipidemia

- Renal disease

- Liver disease

Miscellaneous

- Surgery and trauma

- Smoking

- Drug and alcohol abuse

- Structural abnormalities of the penis
How to Assess a Diabetic Patient Presenting with ED?

The risk of peripheral vascular disease, cerebrovascular disease and Coronary Artery Disease (CAD) are high with men suffering from ED which occurs on average three years earlier than symptoms of coronary artery disease. Silent ischemic heart disease is very common among diabetic patients with erectile dysfunction. Both CAD and ED may happen as a resultof underlying endothelial dysfunction and also share many risk factors such as hyperlipidemia, high blood pressure, diabetes, depression, obesity, poor diet, excess alcohol drinking and cigarette smoking ${ }^{28}$.

Following medical assessment are recommended from cardiovascular perspectives:

i) Blood pressure measurement

ii) Blood sugar fasting test

iii) Glycosylated hemoglobin test

iv) Lipid profile test

v) Waist circumference measurement

vi) Thyroid function test

vii) Testosterone

viii) ECG

ix) Echocardiogram.

The diagnosis of ED can be supported by questionnaires like The International Index of Erectile Function (ILEF).

The ILEF is a valid measure of male ED and consists of 15 points questionnaire ${ }^{29}$ :

i) Erectile Function- 6 Questions.

ii) Orgasmic functions- 2 Questions

iii) Sexual desire- 2 Questions

iv) Intercourse satisfaction- 3 Questions

v) Overall sexual satisfaction- 2 Questions.

The achieved score ranges from 5 to 25 and enables to classify ED into 5 categories from normal function (22-25) through mild (17-21) and mild to moderate (12-16) dysfunction to moderate (8-11) and severe ED (5-7) ${ }^{29}$.

Erectile Dysfunction as Surrogate Markers of

Atherosclerosis and CAD (Figure 3)

It is estimated that around 18 million men suffer from ED in the $\mathrm{US}^{30}$. ED is frequent and increases as men age. CVD remains the most important cause of death in the US ${ }^{31}$.

It is well known that CVD forecast incidences of ED, as both share the same risk factors, including age, diabetes, dyslipidemia, hypertension, obesity and smoking ${ }^{32}$.

On the other hand, ED has also been hypothesized to be a marker of further cardiovascular events ${ }^{33}$. Many studies reported the relation of ED and CVD risk as being statistically significant ${ }^{34}$.

A meta-analysis of 12 prospective cohort studies proved that ED is significantly related to an increased incidence of CHD (46\%) CVD (48\%) stroke (35\%) and all causes mortality (19\%) compared to the control group ${ }^{35}$.

Artery size hypothesis, as atherosclerosis affects all main vascular beds to the same limit, penile arteries (Small diameter) are affected earlier than coronary arteries and so ED symptoms appear before $\mathrm{CVD}^{36}$. 
Endothelial dysfunction causes an imbalance between vasoconstriction and vasodilation in the vascular tone associated with a decreased nitric oxide activity and increased AT II and endothelinactivity.The same vascular/endothelial injuries that happen in coronary arteries are likely to happen in the cavernosal arteries supplying the penile erectile tissues ${ }^{37,38}$.

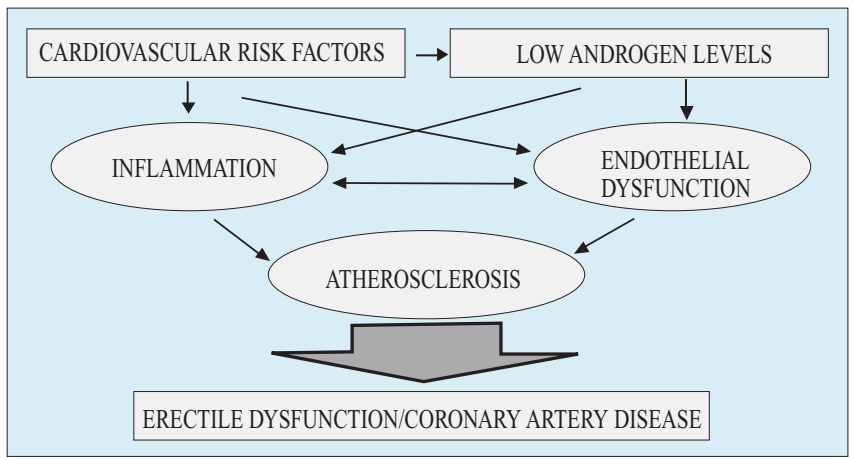

Figure 3 : The association of atherosclerosis and erectile dysfunction $^{39}$

CVD Modifiable Risk Factors are Common with ED It is of clinical importance that ED is an independent indicator of increased risk additionally to the traditional risk factors ${ }^{40,41}$.

In a meta-analysis and systematic review including six clinical trials from four countries $(740$ participants $)$ lifestyle modification and pharmacological therapy (e.g statins) were associated with sexual function improvement, which also have been shown to decrease risk of CVD and mortality ${ }^{42}$.

Men with ED therefore give a chance to identify CVD risk factors and start targeted risk-reduction lifestyle changes. By decreasing the risk of ED this might be an unexplored motivation to tackle CVD risk factors, adding 'life to years' as well as years to life.

The importance of decreasing risk factors remains essential to individual vascular good health including sexual vascular health $^{43}$. the triad of ED, CVD and endothelial dysfunction highlights to include ED in all CVD risk calculators ${ }^{44}$.

The link between ED and CVD has further been analyzed in the following two reports in 2001 that recommended that ED could be a sign for asymptomatic coronary artery disease ${ }^{45}$, 46 . In about two-thirds of cases following reports identified ED prior to $\mathrm{CAD}$, with $\mathrm{ED}$ time interval to $\mathrm{CAD}$ symptoms (2-3 years) and to a CVD (3-5 years). Also, ED severity correlates with CAD severity ${ }^{47-50}$.

\section{Common CVD modifiable risk factors ${ }^{40}$}

\begin{tabular}{|l|}
\hline Hypertension \\
Diabetes \\
Hyperlipidaemia \\
Cigarette smoking \\
Excess alcohol consumption \\
Lack of physical exercise \\
Obesity \\
Poor diet \\
Psychological stress, with depression \\
\hline
\end{tabular}

\section{Relationship Between ED and CVD- Review of Evidence}

As CVD and ED are found together more frequently, especially with diabetic patients, all men should be asked about their ED because it is considered as a warning sign of CVD and 2-5 years risk reduction can be achieved with early management ${ }^{40,51}$.

In a systemic review of studies, Giorgio Gandaglia and colleagues found close association between ED and CVD and concluded that as ED precedes the onset of CVD, it is to be considered as an early marker of $\mathrm{CVD}^{39}$.

Thompson et al evaluated the association between ED and subsequent CVD in 9457 men in the Prostate Cancer Prevention Trial. After 5 years $57 \%$ of individuals developed ED and men with incident ED were at significantly increased risk of CAD with a HR of $1.25^{52}$.

In a prospective longitudinal study by Inman and colleagues, 1406 men without known CAD were evaluated for ED and the role of age in this association. They concluded that ED in young men is associated with markedly increased risk of cardiac events in the future and calls for cardiovascular risk factor screening and intervention are required ${ }^{48}$.

Relation between ED and CVD- review of trials ${ }^{40,51}$

\begin{tabular}{|c|c|c|}
\hline The study & Result of the study & Conclusion \\
\hline MMAS & $\begin{array}{l}43 \% \text { deaths due to CVD } \\
\text { in menwith ED after } 15 \\
\text { years of follow-up }\end{array}$ & $\begin{array}{l}\text { ED is one of the cardiovascular } \\
\text { risk factors and predicted } \\
\text { mortality of CVD }\end{array}$ \\
\hline $\begin{array}{l}\text { ONTARGET/ } \\
\text { TRANSEND } \\
\text { Trial }\end{array}$ & $\begin{array}{l}\text { ED was significantly } \\
\text { predictiveof cardio- } \\
\text { vascular death, MI, stroke } \\
\text { and HF in men with CVD. }\end{array}$ & $\begin{array}{l}\text { Aggressive risk reduction } \\
\text { treatment for men with ED and } \\
\text { CVD. }\end{array}$ \\
\hline COBRA & $\begin{array}{l}\text { Tested the different rate } \\
\text { of ED in the clinical } \\
\text { presentation of } \\
\text { CVD and the vessel }\end{array}$ & $\begin{array}{l}47 \% \text { of ED in CAD patients. } \\
24 \% \text { of ED have normal coronary } \\
\text { angiography. } \\
22 \% \text { of ED in ACS with one } \\
\text { vessel disease. } \\
55 \% \text { of ED in ACS and multi- } \\
\text { vessel disease. } \\
65 \% \text { of ED have Chronic } \\
\text { coronary artery disease. }\end{array}$ \\
\hline
\end{tabular}

Investigations of ED

Most but not all patients need investigations, proper history taking and a thorough physical examination is essential approach of ED.

\section{Laboratory Studies}

Endocrine assessment is important in patients presenting a loss of libido, depression and decreased secondary sexual characteristics.

Early morning as well as free bio-available testosterone level is important along with serum chemistry, lipid profile, PSA, urinalysis, Sex Hormone Binding Globulin (SHBG) Prolactin, FSH, LH, TSH, and $\mathrm{HbA1C} \mathrm{C}^{53,54}$. 


\section{Injection of prostaglandin E1}

This is a test done to assess the penile function, by injecting prostaglandin E1 into one of the corpora cavernous, if the penile circulation is normal or adequate, erection should happen within minutes ${ }^{55,56}$.

\section{Biothesiometry}

The sensitivity of the penile skin to vibration is used as a single nerve function-screening test; it detects the penile sensory deficit.

\section{Ultrasonography}

Blood flow within cavernosal arteries is measured before and after injection of a vasodilator by duplex ultrasonography.

\section{Nocturnal Penile Tumescence Testing}

Several bands are placed around the penis connected to certain device (Rigiscan monitor). The patient should wear it over 2-3 nights then the strength and duration of erection is measured. Inadequate or absent erection indicates organic cause, whereas normal erection means psychological ${ }^{57}$.

Other studies like angiography are recommended if the patient is a candidate for vascular surgery, and neurological testing in some cases is important.

\section{Management of ED}

Life style modification, smoking cessation, reducing stress, regular exercise and weight reduction. The treatment is based on the patients' health and capacity to bear the treatment.

Urologists can help patients in selecting the best treatment available.

First Line Treatment ${ }^{58}$

\section{- Phosphodiesterase Type 5 Inhibitor (PDE5 Inhibitors)}

(Sildenafil, Vardenafil, Tadalafil)

FDA recommended agents which are contraindicated with Nitrates, patients with angina, alpha blockers with other PDE5 inhibitors.

These medications enhance the effect of NO and are least effective in diabetics in comparison to other patients with ED.

\section{- Testosterone Supplementation (In clinical hypogonadism)}

\section{Second Line Treatment}

\section{- Vacuum pump erection device}

The rate of satisfaction with this treatment is between 20$50 \% 59$. The pump generates a vacuum that draws blood to the penis and makes it erect. Contraindicated in patients with sickle cell anemia and those under anticoagulant therapy ${ }^{60}$.

\section{- Intra Urethral Suppositories of Prostaglandin E1}

Least effective even in clinical practice ${ }^{61}$.

\section{- Intra Cavernous Injection Therapy}

Vaso-active agents like PGE1 are efficacious if the blood vessels of the corpora cavernosa are healthy. It is administered by injecting into the penis. Adverse effect involves penile pain.

\section{- Penile Implant Surgery}

If all the above-mentioned treatment fails then refer to an urologist for an inflatable penile prosthesis implant ${ }^{58}$.

Consider angioplasty in patients with penile artery stenosis, which was $60 \%$ effective in Wang et $\mathrm{al}^{62}$.

\section{CONCLUSION}

Coronary artery disease is the leading cause of death in many countries. It has been shown to share common risk factors and pathophysiological mechanisms with erectile dysfunction. The recent research data suggests that ED may be the first sign of occult cardiovascular disease. This should prompt a physician to perform a detailed evaluation and targeted risk factor modification in the 'at risk' groups of patients which could long-term reduce the high mortality and morbidity rates associated with CAD. For a developing country like Bangladesh, the high prevalence of ED and CVD could further attribute to increasing healthcare costs associated with a substantial decreased quality of life owing to the escalating morbidity and mortality if practical lifestyle measures are not taken. The above described association between CAD and ED highlights again the importance of lifestyle adjustments and patient education regarding diet and exercise, tobacco use, blood pressure and cholesterol targets in the holistic approach to patient's care, especially in the context of underlying diabetes mellitus.

\section{DISCLOSURE}

All the authors declared no competing interest. 


\section{REFERENCES}

1. Selim S, Chowdhury SH, Azad AK, Chowdhury MAJ, Rahaman FR, Karim N. Frequency and Riskfactors of Erectile Dysfunction in Bangladeshi Diabeticmen. J Endocrinol Diabetes Obes. 2015; 3(3):1075.

2. Degroat WC, Booth AM. Physiology of male sexual function. Ann Intern Med. 1980; 29(2):329-331.

3. Dean RC, Lue TF. Physiology of penile erection and pathophysiology of erectile dysfunction. UrolClin North Am. 2005; 32 (4):374.

4. Lauman EO, Paik A, Rosen RC. Sexual dysfunction in the United States: Prevalence and predictors. JAMA. 1999; 58:603-607.

5. Bacon CG, Hu FB, Giovannucci E. A study on association of type and duration of diabetes mellitus with ED in a large cohort of men done in Kenya. Diabetes Care. 2003; 25:1458-1463.

6. Feldman HA, Goldstein I, Hatzichristou DG et al. Impotence and its medical and psychosocial correlates: Results of the Massachusetts Male Aging Study J Urol. 1994;151:54-61.

7. Chu NV, Edelman SV. Diabetes and ED. Clinical Diabetes January. 2001;19(1):45-47.

8. Johannes CB, Araujo AB, Feldman HA et al. Incidence of ED in men 40 to 69 years old; longitudinal results from the Massachusetts Male Aging Study J Urol. 2000;163:460-463.

9. Malarige LS, Levy JC. Journal of Sexual Medicine. 2009; 6(5):1232-1247.

10. Fedele D, Bortolotti A, Coscelli C, Santeusanio F, Chatenoud L, Colli E et al. ED in type 1 and type 2 diabetes in Italy on behalf of GruppoHaliano Studio Deficit Erectile in diabetics. International Journal of Epidemiology. 2000; 29(3):524-531.

11. Miccolo R, Giampeto O, Tognarelli M, Rossi B, Giovannitti G, Navalesi R. Prevalence and type of sexual dysfunctions in diabetic males: A standardized clinical approach. Journal of Medicine. 1987; 18(5-6):305-321.

12. Fung MM, Bettencourt R, Barrett-Connor E. Heart disease risk factors predict erectile dysfunction 25 years later The Rancho Bernardo Study. J Am CollCardiol. 2004;43(8):1405-1411.

13. McCulloch DK, Campbell IW, Wu FC, Prescott RJ, Clarke BF. The prevalence of diabetic impotence. Diabetologia. 1980;18(4):279.

14. Riley PJ, Layne CK, Miller K, Walker L. Prevalence and risk factors associated with erectile dysfunction in diabetic men attending clinics in Kingston, Jamaica. Journal of Diabetology. 2012; 2:2.

15. Thorve VS, Kshirsagar AD, Vyawahare NS, Joshi VS, Ingale KG, Mohite RJ. Diabetes-induced erectile dysfunction: Epidemiology, pathophysiology and management. J Diabetes Complications. 2011; 25(2):129-136.

16. Vickers MA, Wright EA. Erectile dysfunction in the patient with diabetes mellitus. Am J Manag Care. 2004;10:S3-11 quiz S12-6.

17. De Anglies L, Marfella MA, Siniscalchi M et al. Erectile and endothelial dysfunction in type 2 diabetes. Diabetologia. 2001; 44:1155-1160.

18. Lue TF. Erectile Dysfunction. N Engl J Med. 2000; 342 -1802-1813.

19. Virag R, Bouilly P, Frydman D. Is impotence an arterial disorder? A study of arterial risk factors in 440 impotent men. Lancet. $1985 ; 1: 181$.

20. Khaw KT, Dowsett ME Folkerd et al. Endogenous testosterone and mortality due to all causes, CVD, and cancer in men: European prospective investigation into cancer in Norfolk (EPIC-Norfolk) Prospective Population Study. Circulation. 2007;116:2694-2701.

21. Corona G, Rastrelli G, Monami M et al. Hypogonadism as a risk factor for cardiovascular mortality in men: a meta-analytic study; Eur J Endocrinol. 2011;165:687-701.

22. Vlachopoulos CN. Ioakeimidis D. Terentes-Printzios, et al. Plasma total testosterone and incident cardiovascular events in hypertensive patients. Am J Hypertens. 2013;26:373-38.

23. Traish AM, Goldstein I, Kim NN. Testosterone and erectile function: From basic research to a new clinical paradigm for managing men with androgen insufficiency and ED. EurUrol. 2007;52:54-70.

24. Mirone VC, Imbimbo F, Fusco P, Verze M, Creta GT. Androgens and morphologic remodeling at penile and cardiovascular levels: A common piece in complicated puzzles. EurUrol. 2009;56:309-316.

25. Vlachopoulos $\mathrm{C}$, Aznaouridis $\mathrm{K}$, Ioakeimidis $\mathrm{N}$ et al. Unfavourable endothelial and inflammatory state in ED patients with or without CAD. Eur Heart J. 2006;27:2640-2648.

26. Hogan MJ, Wallin JD, Baer RM. Antihypertensive therapy and male sexual dysfunction. Psychosomatics. 1980; 21:234-237.

27. Kochar MS, Zeller JR, Itskovitz HD. Prazosin in hypertension with and without methyldopa. Clin Pharmacol. Ther. 1979; 25: 143-148.

28. Graham J. Erectile dysfunction and cardiovascular disease. Arab Journal of Urology. 2013; 3(11):212-216.

29. Cappelleri JC, Rosen RC, Smith MD, Mishra A, Osterloh IH. Diagnostic Evaluation of the erectile function-Domain of the international index of erectile function. Urology. 1999;54:346-351.

30. Selvin E, Burnett AL, Platz EA. Prevalence and risk factors for ED in the US. Am J Med. 2007; 120(2):151-157.

31. Floyd-Jones D, Adams RJ, Brown. Heart disease and stroke statistics—-2010 update: A report from the American Heart Association. Circulation. 2010; 121:e46-e215. 


\section{REFERENCES}

32. Montorsi P, Ravagnani PM, Galli S. Common grounds for erectile dysfunction and coronary artery disease. CurrOpin Urol. 2004; 14:361-365.

33. Kirby M, Jackson G, Betteridge J, Friedli K. Is ED a marker for CVD? Int J ClinPract. 2001; 55:614-618.

34. Guo W, Liao C, Zou Y. ED and risk of clinical CVD events: A meta-analysis of seven cohort studies. J Sex Med. 2010; 7:2805-2816.

35. Dong JY, Zhang YH, Qin Q. ED and Risk of CVD. Meta-analysis of Prospective Cohort Studies. J Am CollCardiol. 2011; 58(13):1378-1385.

36. Montorsi P, Ravagnani PM, Galli S. The artery size hypothesis: a macrovascular link between ED and CAD. Am J Cardiol. 2005; 96:19M-23M.

37. Kirby M, Jackson G, Simonsen U. Endothelial dysfunction links ED to heart disease. Int J ClinPract. 2005; 59:225-229.

38. Levine LA, et al. Importance of asking questions about erectile dysfunction, American Journal of Cardiology. 2000; 86:1210-1213.

39. Gandaglia G, Briganti A, Jackson G, Kloner R, Montorsi F et al. A Systematic Review of the Association between Erectile Dysfunction and Cardiovascular Disease. European Urology. 2014; 65(1):968-978.

40. Jackson G, Boon N, Eardley I, Kirby M, Dean J, Hackett G et al. ED and CAD prediction: evidence-based guidance and consensus. Int J Clin Pract. 2010; 64:848-857.

41. Nehra A, Jackson G, Miner M, Billups KL, Burnett AL, Buvat J et al. Consensus recommendations for the management of ED and CVD Mayo Clin Proc. 2013;87:766-778.

42. Gupta BP, Murad MH, Clifton MM, Prokop L, Nehra A, Kopecky SL. The effect of lifestyle modification and CVD factor reduction on ED: A systematic review and meta-analysis. Arch Intern Med. 2011; 171:1797-1803.

43. Jackson G. The importance of risk factor reduction in ED. CurrUrol Rep. 2007; 8:463-466.

44. Vlachopoulos C, Ioakeimidis N, Terentes-Printzios D, Stefanadis C. The triad: ED - endothelial dysfunction - CVD. Curr Pharm Des. 2008; 14:3700-3714.

45. O'Kane D, Jackson G. ED: is there silent obstructive CAD? Int J Clin Pract. 2001; 55:219-220.

46. Kirby M, G. Jackson G, Betteridge J, Friedli K. Is ED a marker for CVD? Int J Clin Pract. 2001; 55:614-618.

47. Hodges LD, Kirby M, Solanki J, O'Donnell J, Brodie DA. The temporal relationship between ED and CVD.Int J Clin Pract. 2007; 61:2019-2025

48. Inman BA, Sauver JL, Jacobson DJ, McGree ME, Nehra A, Lieber MM. A population-based, longitudinal study of ED and future CAD Mayo Clin Proc. 2009; 84:108-113.

49. Ponholzer C, Temml R, Obermayr C, Wehrberger S. Is ED an indicator for increased risk of CAD and stroke? Eur Urol. 2005; 48:512-518.

50. Montorsi P, Ravagnani PM, Galli S, Rotatori F, Veglia F, Briganti A et al. Association between ED and CAD. Role of coronary clinical presentation and extent of coronary vessels involvement: The COBRA trial.Eur Heart J. 2006; 27:2632-2639.

51. Vlachopoulos C, Jackson G, Stefanadis C, Montorsi P. Erectile dysfunction in the cardiovascular patient. Eur Heart J. 2013; 34(27):2034-2046.

52. Thompson IM, Tangen CM, Goodman PJ. Erectile dysfunction and subsequent cardiovascular disease. JAMA. 2005; 294(23):2996-3002.

53. Rizvi K, Hampson JP, Harvey JN. Do lipid-lowering drugs cause ED? A systematic review. FamPract. 2002; 19(1):95-98.

54. Qaseem A, Snow V, Denberg TD, Casey DE Jr, Forciea MA, Owens DK et al. Hormonal testing and pharmacologic treatment of ED: A clinical practice guideline from the American College of Physicians. Ann Intern Med. 2009; 151(9):639-649.

55. Gutierrez P, Hernandez P, Mas M. Combining programmed intracavernous PGE1 injections and sildenafil on demand to salvage sildenafil nonresponders. Int J Impot Res. 2005; 17(4):3548.

56. Lin CS, Ho HC, Chen KC, Lin G, Nunes L, Lue TF. Intracavernosal injection of vascular endothelial growth factor induces nitric oxide synthase isoforms. BJU Int. 2002; 89(9):955-960.

57. Swindle RW, Cameron AE, Lockhart DC, Rosen RC. The psychological and interpersonal relationship scales: assessing psychological and relationship outcomes associated with ED and its treatment. Arch Sex Behav. 2004; 33(1):19-30.

58. David F, Penson MD, Hunter. Erectile Dysfunction in Diabetic Patients. Diabetes Spectrum. 2004; 17(4): 225-230.

59. Levine LA, Dimitriou RJ. Vacuum constriction and external erection devices in ED. UrolClin North Am. 2001; 28:335-338.

60. Heidelbaugh JJ. Management of Erectile Dysfunction. Am Fam Physician. 2010; 81(3):305-312.

61. Fulgham PF, Cochran JS, Denman JL, Feagins BA, Gross MB et al. Disappointing initial results with transurethral alprostadil for ED in a urology practice setting. J Urol.1998;160:2041-2046.

62. Wang TD, Lee WJ, Yang SC, Lin PC, Tai HC et al. Safety and six-month durability of angioplasty for isolated penile artery stenosis in patients with ED: A first-in-man study. Euro Intervention. 2014;10(1):147-156. 